\title{
COMUNIDADES LENHOSAS NO CERRADO SENTIDO RESTRITO EM DUAS POSIÇÕES TOPOGRÁFICAS NA ESTAÇão ECOLÓGICA do JaRdim BotÂnico de Brasília, DF, Brasil
}

\author{
Manoel Cláudio da Silva Júnior ${ }^{1,2}$ \& Thaise Rachel Sarmento ${ }^{1}$
}

\begin{abstract}
Resumo
(Comunidades lenhosas no cerrado sentido restrito em duas posições topográficas na EEJBB, DF, Brasil) A topografia afeta o regime hídrico e propriedades edáficas determinantes da vegetação do cerrado. Este estudo avaliou a distribuição espacial de árvores do cerrado sensu stricto em duas posições topográficas, interflúvio (I) e vale (V) na Estação Ecológica do Jardim Botânico de Brasília. No total 15 parcelas, 20x50m cada, foram locadas, 10 no cerrado I e cinco no cerrado $\mathrm{V}$, para amostrar árvores, $\mathrm{DB}_{(30 \mathrm{~cm})} \geq 5 \mathrm{~cm}$. O número de árvores por parcela serviu para a classificação por TWINSPAN. A comparação da densidade e área basal de espécies preferenciais aos cerrados I e V em 18 localidades elegeu aquelas potencialmente indicadoras de condições ambiente no Brasil central. A topografia contribuiu para diferenças florísticas e estruturais nas comunidades I e V. Para o interflúvio foram indicadoras Blepharocalyx salicifolius, Dalbergia miscolobium, Miconia ferruginata, M. pohliana, Piptocarpha rotundifolia, Ouratea hexasperma, Pterodon pubescens, Qualea parviflora e Sclerolobium paniculatum em Latossolos. Byrsonima coccolobifolia, Caryocar brasiliense e Erythroxylum suberosum em Latossolos, solos Litólicos ou arenosos. Pouteria ramiflora em Latossolos e Neossolos Quatzarênicos. Para o vale e Cambissolos foram indicadoras Dimorphandra mollis, Eremanthus glomerulatus, Eriotheca pubescens, Guapira noxia, Plenckia populnea, Qualea multiflora e Symplocos rhamnifolia. As espécies Byrsonima verbascifolia, Kielmeyera coriacea, Qualea grandiflora, Stryphnodendron adstringens e Schefflera macrocarpa foram generalistas.
\end{abstract}

Palavras-chave: árvores, topografia, espécies indicadoras de ambientes, densidade, área basal.

\section{Abstract}

(Cerrado strictu sensu woody communities in two land positions in the Brasília Botanic Gaedens Ecologuical Station, Federal District, Brazil) Topography affects moist regime and edaphic properties determinants of the cerrado sensu stricto vegetation. This study assessed trees spatial distribution in two topographic positions, interfluvial (I) and valley slope (V), in the Ecological Station of the Brasília Botanical Garden, Brasília, Brazil. In the total 15 plots, 20x50 m each, were located, 10 in area I and $5 \mathrm{in}$ area $\mathrm{V}$, to survey trees, $\mathrm{BD}_{(30 \mathrm{~cm})} \geq 5 \mathrm{~cm}$. Species number of trees per plot was used to a TWINSPAN classification. Density and basal area of cerrados I and V preferential species were compared in 18 areas in Central Brazil to elect those potentialy indicators environmental conditions. Topography contributed to floristic and structural differences within I and V communities. Interfluvial indicators were Blepharocalyx salicifolius, Dalbergia miscolobium, Miconia ferruginata, M. pohliana, Piptocarpha rotundifolia, Ouratea hexasperma, Pterodon pubescens, Qualea parviflora and Sclerolobium paniculatum for Latossols. Byrsonima coccolobifolia, Caryocar brasiliense and Erythroxylum suberosum for Latossols, Litolic or sand soils. Pouteria ramiflora for Latossols and sandy solis. Valey slope over Cambissols indicators were Dimorphandra mollis, Eremanthus glomerulatus, Eriotheca pubescens, Guapira noxia, Plenckia populnea, Qualea multiflora and Symplocos rhamnifolia. Widely distributed species were Byrsonima verbascifolia, Kielmeyera coriacea, Qualea grandiflora, Stryphnodendron adstringens and Schefflera macrocarpa.

Key words: trees, topography, environment indicator species, density; basal area.

\section{INTRODUÇÃo}

As savanas tropicais ocorrem, em sua maioria, sobre superfícies antigas e modificadas, resultado de milhões de anos de processos geomorfológicos na África, Ásia, Austrália e nas Américas
(Solbrig 1996). Frost et al. (1986) sumarizaram as relações savana $\times$ ambiente em dois eixos, $o$ primeiro relacionado com a disponibilidade de umidade (PAM) e o segundo com a disponibilidade de nutrientes para as plantas (PAN).

Artigo recebido em 10/2007. Aceito para publicação em 07/2009.

${ }^{1}$ Universidade de Brasília, Depto. Engenharia Florestal, CP 04357, 70910-900, Brasília, DF. mcsj@unb.br ${ }^{2} \mathrm{CNPq}$ - Bolsa, Pesquisador II. 
No contexto da classificação da vegetação mundial o cerrado é Savana Tropical Úmida, apresenta fisionomias e flora próprias (Eiten 1994). A sazonalidade na precipitação, a drenagem e a fertilidade do solo, a profundidade do lençol freático, a ocorrência de fogo, as variações climáticas no quaternário e os fatores antrópicos foram salientados como determinantes da vegetação do cerrado (Eiten 1972; Ribeiro \& Walter 2008; Henriques \& Hay 2002; Ledru 2002; Miranda et al. 2002; Oliveira-Filho \& Ratter 2002).

Em sua distribuição geográfica original estende-se por mais de $20^{\circ}$ de latitude, em ampla variação de altitude (Felfili \& Silva Júnior 2005). No total, o cerrado ocupa área de aproximadamente 2 milhões de $\mathrm{km}^{2}$ ou cerca de $23 \%$ do território nacional, extensão esta superada apenas pela Floresta Amazônica com 3,5 milhões de $\mathrm{km}^{2}$ (Ribeiro \& Walter 1998).

O cerrado está entre as mais ricas dentre as savanas do mundo (Ribeiro \& Walter 1998). Devido à riqueza e ao elevado grau de destruição atual, o bioma cerrado foi incluído na lista dos 34 hot spots da biodiversidade mundial (Mittermeier et al. 2005). Riqueza esta listada por Mendonça et al. (1998) em $6.420 \mathrm{e}$ por Walter (2006) em 11.046 espécies de espécies vasculares, distribuídas em formações florestais, savânicas e campestres (Ribeiro \& Walter 1998).

Felfili et al. (1993, 1994, 2001, 2004, 2007), Ratter et al. (1997, 2003), Fonseca \& Silva Júnior (2004) e Ribeiro et al. (2005) conduziram levantamentos para o conhecimento da flora, dos padrões de distribuição geográfica e das relações vegetação $\times$ variáveis ambientais no Cerrado. Entretanto muitas áreas ainda não foram estudadas (Felfili et al. 2007).

O cerrado sentido restrito, em ampla variação de latitude, altitude e classes de solos, ocupa cerca de $65 \%$ da área total da formação do Cerrado (Haridasan 2007). É caracterizado por árvores baixas, tortuosas, inclinadas, com ramificações irregulares e retorcidas, frequentemente com evidências de queimadas (Ribeiro \& Walter 2008). Atualmente, resultado da contínua destruição ocorrida nas últimas décadas, restam poucos remanescentes desta vegetação que se tornaram áreas foco de muitas pesquisas. Estudos florísticos, fitogeográficos e ecológicos nestes remanescentes procuram dar suporte técnico para seleção de áreas prioritárias para conservação e para a recuperação de áreas degradadas (Felfili et al. 2007).

O Distrito Federal, após 44 anos de ocupação, perdeu aproximadamente $73,8 \%$ da cobertura vegetal original e a área protegida em unidades de conservação não atinge os $2 \%$ da sua extensão (Felfili 2000).

O Jardim Botânico de Brasília (JBB) e sua Estação Ecológica (EEJBB), local deste estudo, apresentam vegetação com níveis reduzidos de perturbação. Apresenta, também, a rara presença do cerrado sentido restrito na borda da mata de galeria do córrego Cabeçade-Veado. Franco (2002) associou as maiores coberturas e densidades de árvores no cerrado ao maior uso e disponibilidade de água para a vegetação. Portanto, neste trabalho, assume-se que na borda da mata de galeria na EEJBB há maior disponibilidade de água nos solos, tanto pela situação topográfica no vale quanto pela grande densidade de árvores.

O regime de umidade nos solos é fator importante na organização da vegetação em diferentes ecossistemas (Rodriguez-Iturbe $e t$ al. 2001) e foi considerado fator dominante na organização de comunidades no cerrado sentido restrito na Estação Ecológica de Águas Emendadas no DF (Ferreira et al. 2007).

Neste contexto o presente trabalho avalia a hipótese que o efeito da topografia influencia outros fatores como a disponibilidade de água nos solos contribui para diferenças florísticas e estruturais ao nível de espécies e de comunidades do componente lenhoso do cerrado sentido restrito em duas posições topográficas, interflúvio (I) e vale (V), na Estação Ecológica do Jardim Botânico de Brasília (EEJBB). Nossa estratégia foi encontrar populações com distribuição preferencial nas duas áreas e comparar sua densidade e a área basal em 18 áreas no Brasil Central, para a definição de 
espécies indicadoras potenciais das situações de interflúvio (I) e vale (V).

\section{Material e Métodos}

O Jardim Botânico de Brasília (JBB) situa-se nas coordenadas $15^{\circ} 50^{\prime}-15^{\circ} 55^{\prime} \mathrm{S}$, $47^{\circ} 49^{\prime}-47^{\circ} 55^{\prime} \mathrm{W}$ e 1.056 metros de altitude. Possui área aproximada de 526 ha e já teve parte da sua composição florística e fitossociologia estudadas (Azevedo et al. 1990). Sob a administração do JBB está a Estação Ecológica (EEJBB), com área de cerca de 4.500 ha, contígua ao JBB, na qual o presente trabalho foi desenvolvido.

Segundo Pereira (2008), o clima é do tipo Aw, segundo a classificação de Köeppen, com variações para Cwa e Cwb ou do Zonobioma II de Walter (1986), com cinco meses biologicamente secos. As médias anuais de temperatura e precipitação registradas no período de $1986-2006$ foram de $21,1^{\circ} \mathrm{C}$ e de $1475 \mathrm{~mm}$. O diagrama climático elaborado segundo o método de Walter (1986) está na Figura 1 (Pereira 2008). Em setembro registram-se as mais baixas taxas de umidade com valores próximos a $20 \%$, enquanto na estação chuvosa a umidade do ar é mais alta, entre 70-85 \% (Adámoli et al. 1985).

Os solos predominantes no JBB são os Latossolos Vermelhos (floresta e cerrado), Latossolos Vermelho-Amarelos (campo cerrado e cerrado), Cambissolos (campo limpo, campo cerrado e floresta) e Gleissolos (campo limpo). Em geral, os solos apresentam características em comum como a baixa fertilidade, altos teores de alumínio trocável, acidez elevada e reduzida taxa de matéria orgânica (EMBRAPA 1999).

Em 1997, a vegetação lenhosa do cerrado sentido restrito na EEJBB foi amostrada em 20 parcelas de $20 \times 50 \mathrm{~m}\left(1000 \mathrm{~m}^{2}\right)$ cada (Fonseca \& Silva Júnior 2004) para o inventário permanente com avaliações a cada três anos. Destas, 10 parcelas foram locadas no vale (V), em área mais inclinada na borda da mata de galeria do córrego Cabeça-de-Veado, inferida sob condições de lençol freático mais superficial. As outras 10, no interflúvio (I), em área plana, vertente acima, distante da borda com a mata, inferida sob condições de lençol freático mais profundo. No interflúvio as parcelas foram dispostas de forma sistemática, distante uma da outra em cerca de $100 \mathrm{~m}$. No vale, as parcelas foram locadas em manchas distribuídas ao longo da extensão da mata. Cada parcela foi demarcada com estacas de madeira pintadas em amarelo e numeradas com placas de alumínio, onde foram registrados e identificados todos os indivíduos com diâmetro na base do tronco, a $30 \mathrm{~cm}$ do solo, $\mathrm{DB}_{(30 \mathrm{~cm})} \geq 5 \mathrm{~cm}$. A metodologia foi a mesma aplicada em todos os levantamentos florísticos e fitossociológicos realizados pelo projeto Biogeografia do Bioma Cerrado em outras áreas no cerrado brasileiro (Felfili \& Silva Júnior 1993; Felfili et al. 1994, 2001, 2004, 2007). Destas, 18 áreas foram aqui comparadas com os cerrado I e V da EEJBB.

Em 1998, ocorreu um incêndio que atingiu apenas as parcelas na área I que foi reportado por Fechner (2001), quando 6,31\% dos indivíduos estavam mortos, principalmente aqueles nas menores classes de diâmetro $\left(\mathrm{DB}_{(30 \mathrm{~cm})}<10 \mathrm{~cm}\right)$.

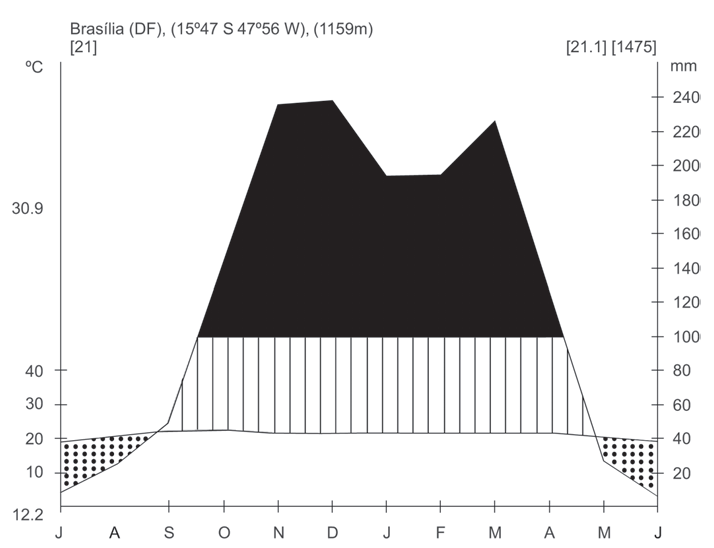

Figura 1 - Diagrama climático de acordo com Walter (1986). Período 1986-2006, na EEJBB, com registros da estação climatológica de Brasília (DF).

Figure 1 - Climatic diagram following Walter (1986) for the period from 1986-2006, in the EEJBB, using data from the climatologic station of Brasília (DF). 
Em 2000, para o presente trabalho, a vegetação foi reavaliada, três anos após a primeira amostragem, em 10 parcelas na área I e em apenas cinco parcelas na área $V$, porque as outras cinco foram perdidas. Das 15 parcelas remanescentes, 10 na área do interflúvio (I) ocorrem sobre Latossolo Vermelho-Escuro e distam da borda da mata de galeria entre cerca de $750 \mathrm{~m}$, parcela 5 e $1500 \mathrm{~m}$ parcela 1 . No vale (V), as parcelas ocorrem sobre Cambissolos e distam da borda da mata de galeria entre cerca de $70 \mathrm{~m}$, parcela 14 e $150 \mathrm{~m}$ parcela 15 . As áreas I e V estão separadas por via que permite acesso a EEJBB (Fig. 2).

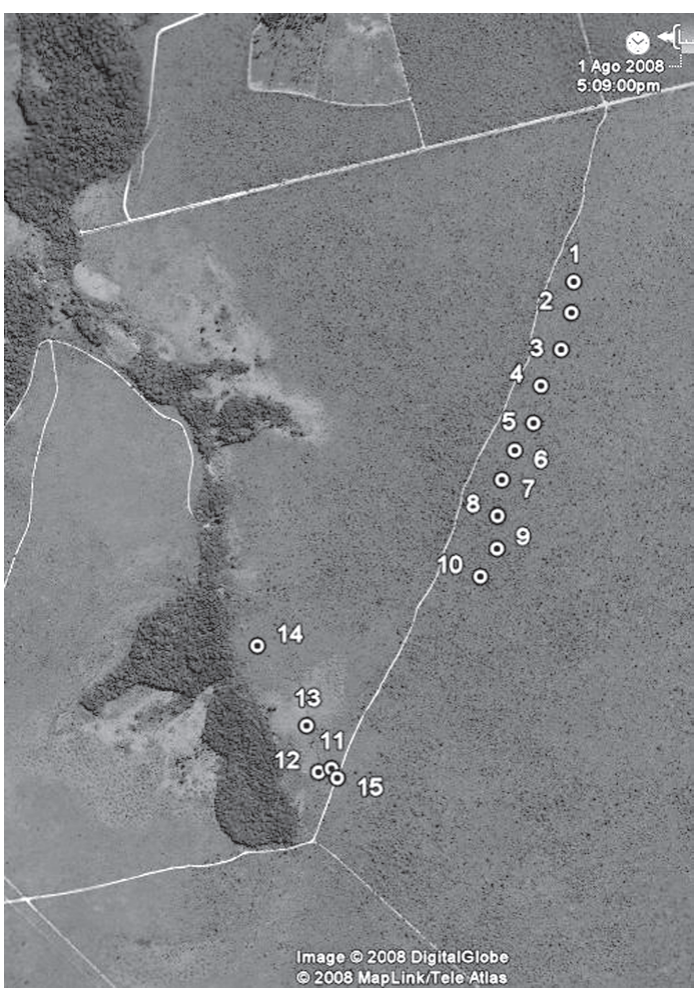

Figura 2 - Parcelas estabelecidas na Estação Ecológica do Jardim Botânico de Brasília. 1-10 no interflúvio, 750 $1500 \mathrm{~m}$ distantes da borda da mata e 11-15 no vale 70$150 \mathrm{~m}$ distantes da borda da mata de galeria do córrego Cabeça-de-Veado. Imagem: www.earth.google.com.

Figure 2 - Sample plots established at the Ecological Station of the Botanical Garden of Brasília. 1-10 in the interfluve, $750-1500 \mathrm{~m}$ far from forest edges and $11-15$ in the valley and $70-150 \mathrm{~m}$ far from edge of a gallery forest at Cabeça-de-Veado stream. Image: www.earth.google.com.
Os dados do número de indivíduos por espécies e por parcelas foram classificados pelo TWINSPAN (Two Way Indicator Species Analysis) (Hill 1979). As interpretações da análise se baseiam na idéia de que a similaridade florística entre duas áreas deveria expressar a sua afinidade ecológica (Jongman et al. 1987). Os grupos na vegetação produzidos pela análise foram aqui referidos como comunidades I e V, com suas respectivas espécies preferenciais.

A densidade (D) e a área basal $(\mathrm{AB})$ das espécies preferenciais I e $\mathrm{V}$ foram comparadas entre 18 áreas de cerrado sentido restrito amostradas da mesma forma no Brasil Central, apresentadas na Tabela $1 \mathrm{com}$ suas respectivas latitudes (S), longitudes (W), altitudes (m) e precipitação anual ( $\mathrm{mm})$.

$\mathrm{Na}$ Chapada Pratinha (CP) as nove áreas estão associadas aos Latossolos (Felfili \& Silva Júnior 1993; Rossi et al. 1998; Felfili et al. 2004), enquanto na Chapada dos Veadeiros (CV) as áreas ocorrem sobre solos Litólicos e Cambissolos (Felfili et al. 2007) e na Chapada do São Francisco (CS) sobre solos arenosos (Felfili et al. 2004).

As comparações da densidade expressaram o sucesso relativo dos processos da floração, polinização, frutificação, dispersão de sementes, germinação, estabelecimento, competição e/ou reprodução vegetativa em cada localidade. As comparações para a área basal complementaram a análise da densidade por expressar a habilidade dos indivíduos estabelecidos em converter recursos do ambiente em crescimento em diâmetro. Felfili et al. $(2004,2007)$ mostraram que a densidade e a área basal foram parâmetros importantes na diferenciação estrutural de áreas do cerrado sentido restrito fisionomicamente homogêneas no Brasil Central.

A distribuição espacial, a densidade e a área basal diferenciais das espécies preferenciais nas duas situações topográficas, interflúvio (I) e vale $(\mathrm{V})$ em conjunto com as comparações da $\mathrm{D}$ e $\mathrm{AB}$ no Brasil central foram a base para a sugestão de espécies potencialmente indicadoras para cada situação. 
Tabela 1 - Latitudes (S), longitudes (W), altitudes (m) e Precipitação (PPT-mm) para as 18 localidades comparadas no Brasil Central.

Table 1 - Latitudes (S), longitudes (W), altitudes (m) and Rainfall precipitation (PPT-mm) for 18 distinct areas compared at Central Brasil.

\begin{tabular}{|c|c|c|c|c|}
\hline Áreas & $\begin{array}{l}\text { Latitude } \\
\text { (S) }\end{array}$ & $\begin{array}{l}\text { Longitude } \\
\text { (W) }\end{array}$ & $\begin{array}{l}\text { Altitude } \\
\text { (m) }\end{array}$ & $\begin{array}{c}\mathbf{P P} \\
(\mathbf{m m})\end{array}$ \\
\hline \multicolumn{5}{|l|}{ Chapada Pratinha (CP) } \\
\hline Parque Nacional de Brasília-DF (PNB) & $15^{\circ} 37^{\prime}-15^{\circ} 45^{\prime}$ & $47^{\circ} 54^{\prime}-47^{\circ} 59^{\prime}$ & 1100 & 1552 \\
\hline Estação Ecol. Águas Emendadas-DF (AE) & $15^{\circ} 31^{\prime}-15^{\circ} 35^{\prime}$ & $47^{\circ} 32^{\prime}-47^{\circ} 37^{\prime}$ & 1100 & 1552 \\
\hline Parque Burle Marx-DF (BM) & $15^{\circ} 37^{\prime}-15^{\circ} 45^{\prime}$ & $47^{\circ} 54^{\prime}-47^{\circ} 59^{\prime}$ & 1100 & 1552 \\
\hline Fazenda Água Limpa-DF (FAL) & $15^{\circ} 56^{\prime}-15^{\circ} 59^{\prime}$ & $47^{\circ} 55^{\prime}-47^{\circ} 58^{\prime}$ & 1100 & 1425 \\
\hline Reserva Ecol. IBGE-DF(IBGE) & $15^{\circ} 56^{\prime}$ & $47^{\circ} 56^{\prime}$ & $1048-1160$ & 1436 \\
\hline APA do Paranoá-DF (APA) & $15^{\circ} 45^{\prime}-15^{\circ} 46^{\prime}$ & $47^{\circ} 50^{\prime}-47^{\circ} 51^{\prime}$ & $1000-1050$ & 1450 \\
\hline Paracatu-MG (PR) & $17^{\circ} 00^{\prime}-17^{\circ} 20^{\prime}$ & $46^{\circ} 45^{\prime}-47^{\circ} 07^{\prime}$ & 900 & 1438 \\
\hline Patrocínio-MG (PT) & $18^{\circ} 47^{\prime}-18^{\circ} 45^{\prime}$ & $46^{\circ} 20^{\prime}-47^{\circ} 09^{\prime}$ & 950 & 1438 \\
\hline Silvânia-GO (SI) & $16^{\circ} 30^{\prime}-16^{\circ} 50^{\prime}$ & $48^{\circ} 30^{\prime}-48^{\circ} 46^{\prime}$ & 1050 & 1552 \\
\hline \multicolumn{5}{|l|}{ Chapada dos Veadeiros (CV) } \\
\hline Alto Paraíso-GO (AP) & $14^{\circ} 00^{\prime}-14^{\circ} 10^{\prime}$ & $47^{\circ} 20^{\prime}-47^{\circ} 58^{\prime}$ & 1200 & 1500 \\
\hline Vila Propício-GO(VP) & $15^{\circ} 16^{\prime}-15^{\circ} 26^{\prime}$ & $48^{\circ} 40^{\prime}-49^{\circ} 04^{\prime}$ & $750-1100$ & 1500 \\
\hline PN Chapada dos Veadeiros-GO (PNCV) & $13^{\circ} 50^{\prime}-14^{\circ} 12^{\prime}$ & $47^{\circ} 24^{\prime}-47^{\circ} 48^{\prime}$ & $620-1650$ & 1500 \\
\hline Serra da Mesa-GO (SM) & $13^{\circ} 35^{\prime}-13^{\circ} 50^{\prime}$ & $48^{\circ} 10^{\prime}-48^{\circ} 22^{\prime}$ & $450-1100$ & 1500 \\
\hline Serra Negra-GO $(\mathrm{SN})$ & $14^{\circ} 59^{\prime}-15^{\circ} 02^{\prime}$ & $48^{\circ} 10^{\prime}-48^{\circ} 22^{\prime}$ & $450-1100$ & 1500 \\
\hline \multicolumn{5}{|l|}{ Chapada São Francisco (CF) } \\
\hline Correntina-BA $(\mathrm{CO})$ & $13^{\circ} 31^{\prime}-13^{\circ} 32^{\prime}$ & $45^{\circ} 22^{\prime}-45^{\circ} 25^{\prime}$ & 586 & 1085 \\
\hline Formosa do Rio Preto-BA (RP) & $11^{\circ} 06^{\prime}-11^{\circ} 12^{\prime}$ & $45^{\circ} 18^{\prime}-45^{\circ} 35^{\prime}$ & 550 & 1006 \\
\hline São Desidério-BA (SD) & $12^{\circ} 35^{\prime}-12^{\circ} 46^{\prime}$ & $45^{\circ} 34^{\prime}-45^{\circ} 48^{\prime}$ & $695-775$ & 1121 \\
\hline PN Grande Sertão Veredas-MG/BA(PNSV) & $15^{\circ} 10^{\prime}-15^{\circ} 21^{\prime}$ & $45^{\circ} 45^{\prime}-46^{\circ} 00^{\prime}$ & $700-900$ & 1185 \\
\hline
\end{tabular}

As espécies amostradas foram identificadas e as famílias classificadas de acordo com o sistema do APG II (Angiosperm Phylogeny Group II, 2003). O material botânico foi coletado em 1997 por Fonseca \& Silva Júnior (2004) e depositado nos Herbários do JBB (HEPH) e Universidade de Brasília (UB).

\section{Resultados e Discussão}

De acordo com Sarmento \& Silva Júnior (2006), no total, dentre as 66 espécies amostradas, 56 ocorreram em I e $43 \mathrm{em} \mathrm{V.}$ Não houve coincidências entre as 10 espécies mais importantes em IVI em cada área. A densidade foi de 1388 e 1090 ind.ha $^{-1}$, respectivamente para o I e V. A área basal em I foi de $9,69 \mathrm{~m}^{2}$.ha' $\mathrm{e}^{-1} \mathrm{em} \mathrm{V}$ foi de $6,14 \mathrm{~m}^{2} \cdot \mathrm{ha}^{-1}$.
O índice de diversidade de Shannon \& Wiener $\left(H^{\prime}\right)$ e de equidade de Pielou (J') foram de 3,19 e 3,15 nats.ind ${ }^{-1} / 0,80$ e 0,85 , respectivamente para as áreas de I e V e indicaram a elevada heterogeneidade florística do componente arbóreo nas duas comunidades.

Nunes et al. (2002) avaliaram 10 localidades e calcularam para o cerrado sentido restrito no DF medianas e intervalos de confiança (IC) para a densidade (D) e área basal (AB) de 1007,8 a 1077,8 (1042,8 \pm 35) ind.ha ${ }^{-1}$ de 7,453 a 7,507 (7,48 $\left.\pm 0,027\right) \mathrm{m}^{2}$.ha-1. As densidades I e V e a área basal I estão acima e a área basal $\mathrm{V}$ está abaixo do destes ICs. As estimativas de densidade e de área basal enquadram-se, entretanto, nos limites para outras áreas de cerrado sentido restrito no Brasil Central que variaram entre $552 \mathrm{e}$ 
1396 ind.ha ${ }^{-1}$, respectivamente para o Parque Burle Marx e para a Estação Ecológica de Águas Emendadas, ambos no DF, e em 5,79 a $11,30 \mathrm{~m}^{2} \cdot \mathrm{ha}^{-1}$, respectivamente para o município de Patrocínio (MG) e Silvânia (GO) (Fonseca \& Silva Júnior 2004). Os índices H' e J' também estão dentro do intervalo de variação observado para outras áreas no Brasil Central, que variaram entre 3,15 a 3,76 nats.ind ${ }^{-1}$ e de a 0,75 a 0,86 (Felfili \& Silva Júnior 1993; Felfili et al. 1993, 1994, 2001, 2004, 2007; Rossi et al. 1998). A inclusão dos cerrados I e V na amplitude de variação da D, AB, H' e J' observada para o cerrado sentido restrito no Brasil Central respalda as comparações conduzidas neste trabalho para $\mathrm{D}$ e $\mathrm{AB}$ das espécies preferências I e V com as demais localidades.

\section{O cerrado de Interflúvio (I)}

Apesar da proximidade entre as áreas I e V (Fig. 2), 23 (34,8\%) espécies foram exclusivas ao cerrado I: Blepharocalyx salicifolius (6 ${ }^{\mathrm{a}}$ em IVI) (Humb., Bompl. \& Kunth) O. Berg, Piptocarpha rotundifolia (Less.) Baker ( $\left.7^{\mathrm{a}}\right)$, Pouteria ramiflora (Mart.) Radlk. (9a), Sclerolobium paniculatum Vogel var. subvelutinum Benth. $\left(13^{\mathrm{a}}\right)$, Miconia pohliana Cogn. (14 $)$, Pterodon pubescens (Benth.) Benth. (15 $)$, Caryocar brasiliense A.St.-Hil. (18 $)$, Vochysia thyrsoidea Pohl. (24), Couepia grandiflora (Mart. \& Zucc.) Benth. ex Hook. f. (31'), Hymenaea stigonocarpa Mart. ex Hayne (32 $)$, Aspidosperma macrocarpon Mart. (34 $)$, Salacia crassifolia (Mart. ex Schult.) G. Don (35 ), Erythroxylum deciduum A. St.-Hill. (36 ${ }^{\mathrm{a}}$, Vochysia elliptica Mart. $\left(37^{\mathrm{a}}\right)$, Hancornia speciosa Gomez (39 $)$, Machaerium opacum Vogel $\left(40^{\mathrm{a}}\right)$, Vochysia rufa Mart. (41 $\left.{ }^{\mathrm{a}}\right)$, Rourea induta Planch. (46 $)$, Machaerium acutifolium Vogel (49a), Brosimum gaudichaudii Trécul (53ª), Bowdichia virgilioides Humb., Bompl. \& Kunth $\left(55^{\mathrm{a}}\right)$, Diospyros burchellii Hiern. (56 $\left.{ }^{\mathrm{a}}\right)$ e Kielmeyera speciosa A. St.-Hill. (57 ${ }^{\mathrm{a}}$ ) (Sarmento \& Silva Júnior 2006). É improvável, devido a proximidade das áreas, que a ausência destas espécies no cerrado $\mathrm{V}$ seja consequência da impossibilidade do acesso de sementes e propágulos. O grupo das exclusivas inclui espécies com dispersão anemocórica e zoocórica. Assume-se, então, que características ambientais distintas entre as áreas I e V regulam composição florística e a estrutura diferencial. Henriques (2004) mostrou que $B$. salicifolius, $C$. brasiliense, $P$. rotundifolia foram também exclusivas no cerrado de interflúvio, distante em 250 m da mata de galeria do córrego Taquara na Reserva Ecológica do IBGE, vizinha da EEJBB.

Entre as espécies mais importantes na área I (Sarmento \& Silva Júnior 2006) incluíramse as comparações $\mathrm{I} \times \mathrm{V}$ para quatro destas, Ouratea hexasperma, Dalbergia miscolobium, Qualea parviflora e Miconia ferruginata, e para o grupo das mortas tratadas a seguir.

O. hexasperma $\left(1^{\text {a }}\right)$ ocorreu com 290 ind.ha ${ }^{-1}$ distribuídos nas 10 parcelas, a maior densidade já registrada para a espécie no Brasil Central. Já no cerrado V ocupou a $17^{\mathrm{a}}$ posição com 13 ind.ha-1 ${ }^{-1}$ Nunes et al. (2002) calcularam mediana e intervalo de confiança (IC) de 140,7 \pm 24 ind.ha ${ }^{-1}$ para o DF. A densidade no cerrado I foi 1,76 vezes maior que o limite superior deste $\mathrm{IC}$, enquanto no cerrado $\mathrm{V}$ foi nove vezes menor que o limite inferior do mesmo IC. A área basal no cerrado I foi de $1,561 \mathrm{~m}^{2} \cdot \mathrm{ha}^{-1} \mathrm{ou}$ 1,72 vezes maior que o limite superior, e de $0,059 \mathrm{~m}^{2} \cdot \mathrm{ha}^{-1}$ para o cerrado $\mathrm{V}, 9,37$ vezes menor que o limite inferior do IC de 0,7310 \pm $0,1779 \mathrm{~m}^{2}$.ha ${ }^{-1}$ calculado para $O$. hexasperma no DF (Nunes et al. 2002).

Demonstrou-se, assim, a maior habilidade de $O$. hexasperma em estabelecer indivíduos e crescer nas condições ambientais de interflúvio. Fonseca e Silva Júnior (2004) mostraram que no Brasil Central, populações maiores que 60 ind.ha-1 só foram encontradas no DF. Moreira (1992) registrou a maior importância da espécie em áreas frequentemente queimadas, o que é fato nas unidades de conservação no DF. Na EEJBB, o cerrado I foi queimado em 1998 quando 6,31\% dos indivíduos estavam mortos, principalmente 
aqueles nas menores classes de diâmetro, $\mathrm{DB}_{(30 \mathrm{~cm})}<10 \mathrm{~cm}$ (Fechner 2001). As consequências do incêndio em 1988 foram evidenciadas na comparação $\mathrm{I} \times \mathrm{V}$ para $\mathrm{o}$ grupo das mortas, com $108 \times 29$ ind.ha $^{-1}, 0,742$ $\times 0,166 \mathrm{~m}^{2} \cdot \mathrm{ha}^{-1}$ e $2^{\mathrm{a}} \times 7^{\mathrm{a}}$ posição em IVI, respectivamente.

D. miscolobium com $79 \times 10$ ind.ha $^{-1}$, $0,495 \times 0,047 \mathrm{~m}^{2} \cdot$ ha $^{-1}$ e $3^{\mathrm{a}} \times 18^{\mathrm{a}}$ posições em IVI apresentou-se no DF com populações de $35,9 \pm 7,23$ ind.ha ${ }^{-1}$ e área basal de 0,3259 \pm $0,0631 \mathrm{~m}^{2} \cdot \mathrm{ha}^{-1}$ (Nunes et al. 2002). As estimativas para as áreas I e V estão fora do intervalo destes ICs, o que denota comportamento diferencial em relação às condições ambientais presentes nas duas localidades aqui avaliadas. Assim, registra-se a maior habilidade de D. miscolobium no uso de recursos no ambiente interflúvio.

Q. parviflora com $51 \times 4$ ind.ha ${ }^{-1}, 0,720$ $\times 0,045 \mathrm{~m}^{2} \cdot$ ha $^{-1}$ e $4^{\mathrm{a}} \times 21^{\mathrm{a}}$ na comparação I $\times$ $\mathrm{V}$, ocorre no DF com populações de 72,3 $\pm 13,54$ ind $\mathrm{ha}^{-1}$ e $1,0221 \pm 0,2242 \mathrm{~m}^{2} \cdot \mathrm{ha}^{-1}$ (Nunes et al. 2002). Somente a densidade no interflúvio incluiu-se neste IC. Q. parviflora é espécie de ampla distribuição no cerrado (Felfili et al. 1994, 2001, 2004, 2007; Ratter et al. 2003; Ribeiro et al. 2005) e apresentou D e $\mathrm{AB}$ maiores que a anotada no cerrado I tanto em Latossolos na Chapada Pratinha em altitudes maiores ou menores que $1.000 \mathrm{~m}$ (Felfili et al. 1994) como também em solos litólicos na Chapada dos Veadeiros-GO (Felfili et al. 2001) e solos arenosos na Chapada São Francisco (Felfili et al. 2007). D e AB anotadas para a espécie na EEJBB indicam a maior habilidade em usar os recursos da área de interflúvio.

M. ferruginata, com $57 \times 1$ ind.ha $^{-1} \mathrm{e}$ $0,467 \times 0,020 \mathrm{~m}^{2} \cdot \mathrm{ha}^{-1}$ foi ranqueada na $5^{\mathrm{a}} \mathrm{e}$ $34^{\mathrm{a}}$ posições em IVI na comparação $\mathrm{I} \times \mathrm{V}$. Esta espécie apresentou valores elevados de $D$ e $A B$ na Reserva do IBGE, vizinha da EEJBB em Latossolos e altitudes maior que 1.000 m (Felfili e Silva Júnior 1993) em solos Litólicos na Chapada dos Veadeiros (Felfili et al. 2007).

\section{O cerrado de Vale (V)}

Foram $10(15,2 \%)$ as espécies exclusivas na área V: 15,2\% Myrcia tomentosa (Aubl.) DC. $\left(19^{\mathrm{a}}\right)$, Lafoensia pacari A. St.-Hill. $\left(26^{\mathrm{a}}\right)$, Guapira graciliflora, (Mart. ex J.A. Schmidt) Lundell $\left(30^{\mathrm{a}}\right)$, Tabebuia aurea (Silva Manso) Benth. \& Hook. F. ex S. Moore (31 $1^{\mathrm{a}}$, Neea theifera Oerst. (33 $)$, Heteropterys byrsonimifolia A. Juss. (35a), Pseudobombax longiflorum (Mart. \& Zucc.) A. Robyns (37 $)$, Copaifera langsdorffii Desf. $\left(39^{\mathrm{a}}\right)$, Tocoyena formosa (Cham. \& Schltdl.) K. Schum. $\left(41^{\mathrm{a}}\right)$ e Vernonia ferruginea Less $\left(43^{\mathrm{a}}\right)$. Destas, M. tomentosa foi a melhor ranqueada na $19^{\mathrm{a}}$ posição em IVI e não foi amostrada em outra localidade de cerrado sentido restrito no Brasil Central.

Dentre as espécies mais importantes em V (Sarmento \& Silva Júnior 2006) foram incluídas aqui as comparações $\mathrm{V} \times \mathrm{I}$ para cinco destas: Eriotheca pubescens, Roupala montana, Guapira noxia, Qualea multiflora e Symplocos rhamnifolia. O grupo das mortas foi considerado no item cerrado de interflúvio.

E. pubescens ocorreu nas cinco parcelas $\mathrm{V}(100 \%)$ e com $142 \times 3$ ind.ha- ${ }^{-1}, 0,538 \times 0,008$ $\mathrm{m}^{2} \cdot \mathrm{ha}^{-1}$ e $1^{\mathrm{a}} \times 43^{\mathrm{a}}$ posição na comparação $\mathrm{V} \times$ I. Nunes et al. (2002) calcularam para o DF mediana e IC de 14,5 \pm 6,67 ind.ha $^{-1}$ e 0,1059 $\pm 0,049 \mathrm{~m}^{2} \cdot \mathrm{ha}^{-1}$, para D e AB, respectivamente. $\mathrm{Na}$ área $\mathrm{V}$ na EEJBB densidade foi quase 10 vezes maior e área basal 5,08 maior que a mediana para o DF. No cerrado I a densidade foi 4,8 e área basal foi 13,2 vezes menor que a mediana para o DF.

Henriques (2004), em estudo do gradiente topográfico no cerrado sentido restrito na Reserva Ecológica do IBGE, vizinha da EEJBB - DF, encontrou, em área distante 50 $\mathrm{m}$ da borda da mata de galeria do córrego Taquara, E. pubescens como a mais importante, seguida de Roupala spp., tal qual no cerrado $\mathrm{V}$ neste estudo.

Roupala montana com $48 \pm 34$ ind.ha $^{-1}$ e $0,204 \times 0,123 \mathrm{~m}^{2} \cdot$ ha $^{-1}$ alcançou a $2^{\mathrm{a}}$ e $22^{\mathrm{a}}$ na comparação V $\times$ I. Nunes et al. (2002) encontraram populações medianas de 28,3 \pm 
7,52 ind.ha ${ }^{-1}$ e área basal de 0,1345 $\pm 0,037$ $\mathrm{m}^{2}$.ha' $\mathrm{a}^{-1}$ para o DF. Os valores de D e AB para $\mathrm{a}$ área $\mathrm{V}$ estão acima do limite superior destes ICs, o que salienta sua maior habilidade em explorar os recursos na condição V.

Guapira noxia com $41 \times 12$ ind.ha $^{-1}$ e 0,202 $\times 0,093 \mathrm{~m}^{2}$.ha $\mathrm{a}^{-1}$ ocupou a $3^{\mathrm{a}} \times 26^{\mathrm{a}}$ colocações em IVI na comparação $\mathrm{V} \times \mathrm{I}$. Os valores para o cerrado $V$ estão acima dos limites superiores dos ICs para a D e AB calculados por Nunes et al. (2002) em 19,7 $\pm 6,2$ ind.ha $^{-1}$ e 0,113 \pm $0,033 \mathrm{~m}^{2} \cdot$ ha $^{-1}$, no DF.

Os resultados para Qualea multiflora com $33 \times 14$ ind.ha $a^{-1}$ e $0,182 \times 0,077 \mathrm{~m}^{2} \cdot$ ha $^{-1} \mathrm{e}$ $4^{\mathrm{a}} \times 27^{\mathrm{a}}$ posições em IVI e para Symplocos rhamnifolia com $26 \times 3$ ind.ha ${ }^{-1}$ e $0,235 \times 0,012$ $\mathrm{m}^{2} \cdot \mathrm{ha}^{-1}$ e $5^{\mathrm{a}} \times 47^{\mathrm{a}}$ posições em IVI nas comparações $\mathrm{V} \times \mathrm{I}$ seguem a mesma a interpretação das espécies anteriores.

\section{A classificação pelo TWINSPAN}

A classificação pelo TWINSPAN indicou na primeira divisão, autovalor de 0,373 , dois grupos com as parcelas 1-10 do cerrado I e 11-15 do cerrado $\mathrm{V}$, aqui denominados comunidades I e V. O resultado demonstra estreita relação da vegetação do cerrado sentido restrito com a posição topográfica e com o afastamento da borda da mata de galeria Cabeça-de-Veado na EEJBB. O autovalor superior a 0,30 apóia as diferenças florísticas marcantes entre as comunidades I e V também notada na fitossociologia das duas áreas.

A primeira divisão para as 66 espécies, autovalor de 0,841, indicou aquelas preferenciais para as comunidade I e V (Tab. 2) e as não preferenciais, generalistas ou de ampla distribuição na área, que não respondem às diferentes condições do ambiente nas duas posições topográficas avaliadas.

Sarmento \& Silva Júnior (2008) classificaram as mesmas parcelas pela UPGMA utilizando a presença ou ausência (Índice de Sørensen) e o número de indivíduos (Índice de Morisita) das espécies por parcelas. A análise corroborou a classificação pelo TWINPAN, aqui apresentada, por separar as áreas do I e V em níveis de fusão de 0,50 para ambas as similaridades Sørensen e Morisita. Os resultados mostraram que os grupos I e V apresentaram níveis de fusão abaixo de 0,51 , mediana Sørensen e acima de 0,41 mediana para Morisita calculadas para 100 parcelas com as mesmas dimensões $(20 \times 50 \mathrm{~m})$ aplicadas em 10 localidade com cerrado sentido restrito preservado no DF (Nunes 2001). Henriques (2004) observou a densidade e a dominância de espécies no cerrado sentido restrito fortemente influenciada pela posição topográfica na Reserva Ecológica do IBGE, vizinha à EEJBB. A topografia e sua influência em outras variáveis ambientais como o regime hídrico e características físicas e químicas dos solos devem atuar diferencialmente nas duas áreas e resultar nas diferenças florísticas e estruturais estabelecidas.

\section{Espécies preferenciais ao interflúvio (I)} Byrsonima coccolobifolia Kunth $\left(20^{\mathrm{a}} \mathrm{x}\right.$ $42^{\mathrm{a}}$ IVI em I $\times$ V), Caryocar brasiliense A. St.-Hil. (18), Dalbergia miscolobium Benth. $\left(3^{\mathrm{a}} \times 18^{\mathrm{a}}\right)$, Erythroxylum suberosum A. St.Hill. $\left(10^{\mathrm{a}} \times 25^{\mathrm{a}}\right)$, Miconia ferruginata DC. $\left(5^{\mathrm{a}} \times 34^{\mathrm{a}}\right)$, Miconia pohliana Cogn. $\left(14^{\mathrm{a}}\right)$, Ouratea hexasperma (A. St.-Hil) Baill. ( $1^{\mathrm{a}} \times$ $\left.17^{\mathrm{a}}\right)$, Pterodon pubescens (Benth.) Benth. $\left(15^{\mathrm{a}}\right)$, Pouteria ramiflora (Mart.) Radlk. (9a), Piptocarpha rotundifolia (Less.) Baker ( $7^{\mathrm{a}}$ ) (Tab. 2) foram classificadas como preferenciais à comunidade I em função da sua distribuição diferencial nas áreas I e V. Neste grupo $C$. brasiliense, $M$. pohliana, $P$. pubescens, $P$. ramiflora e $P$. rotundifolia foram também exclusivas ao cerrado I.

A Tabela 3 apresenta as densidades e a Tabela 4 as áreas basais para as espécies preferenciais nas comunidades $\mathrm{I}$ e $\mathrm{V}$ e em outras 18 áreas no Brasil Central.

B. coccolobifolia ocorreu em 17 das 18 localidades, $C$. brasiliense em 14 e $E$. suberosum em todas as 18 áreas comparadas no Brasil Central. Estas espécies apresentaram valores elevados de $\mathrm{D}$ e $\mathrm{AB}$ em áreas nas Chapadas Pratinha (CP), Veadeiros (CV) e São Francisco (CS), indiferentes às variações 
Tabela 2 - Espécies preferenciais ao cerrado sentido restrito de interflúvio (I) e de vale (V), na Estação Ecológica do Jardim Botânico de Brasília (EEJBB). Em cada nível de corte: 1 a 2, 3 a 5, 6 a 10, 11 a 20 e >20 está anotado o número de parcelas $(\mathrm{I}=10 / \mathrm{V}=5)$ em que a espécie foi amostrada.

Table 2 - Preferential species from the cerrado sensu strictu of the interfluve (I) and the valley (V), at the Ecological Station of the Botanical Garden of Brasília (EEJBB). In each cut level: 1 to 2, 3 to 5, 6 to 10, 11 to 20 and $>20$ it is indicated the number of plots $(\mathrm{I}=10 / \mathrm{V}=5)$ in which the species was detected.

\begin{tabular}{|c|c|c|c|c|c|}
\hline \multirow{2}{*}{$\begin{array}{l}\text { Espécies preferenciais } \\
\text { Interflúvio (I) }\end{array}$} & \multicolumn{5}{|c|}{ Níveis e corte (número de indivíduos por parcela) } \\
\hline & 1 a 2 & 3 a 5 & 6 a 10 & 11 a 20 & $>20$ \\
\hline Byrsonima coccolobifolia & $10 / 1$ & $8 / 0$ & * & * & * \\
\hline Caryocar brasiliense & $8 / 0$ & $6 / 0$ & $*$ & $*$ & $*$ \\
\hline Dalbergia miscolobium & * & $10 / 2$ & $8 / 1$ & $2 / 0$ & * \\
\hline Erythroxylum suberosum & $*$ & $9 / 1$ & $5 / 0$ & $*$ & $*$ \\
\hline Miconia ferruginata & $10 / 1$ & $9 / 0$ & $5 / 0$ & $2 / 0$ & $*$ \\
\hline Miconia pohliana & $10 / 1$ & $8 / 0$ & $*$ & $*$ & $*$ \\
\hline Ouratea hexasperma & * & $10 / 2$ & $10 / 1$ & $10 / 1$ & $8 / 0$ \\
\hline Pterodon pubescens & $10 / 1$ & $8 / 0$ & $8 / 0$ & $*$ & $*$ \\
\hline Pouteria ramiflora & $8 / 0$ & $6 / 0$ & $2 / 0$ & $2 / 0$ & $*$ \\
\hline Piptocarpha rotundifolia & $9 / 0$ & $9 / 0$ & $7 / 0$ & $3 / 0$ & $*$ \\
\hline $\operatorname{Vale}(\mathbf{V})$ & 1 a 2 & 3 a 5 & 6 a 10 & 11 a 20 & $>20$ \\
\hline Dimorphandra mollis & $*$ & $1 / 4$ & $0 / 2$ & $*$ & $*$ \\
\hline Erementhus glomerulatus & $3 / 4$ & $0 / 4$ & $0 / 2$ & $*$ & $*$ \\
\hline Eriotheca pubescens & $2 / 5$ & $1 / 4$ & $0 / 4$ & $0 / 4$ & $0 / 2$ \\
\hline Guapira noxia & * & $3 / 5$ & $0 / 3$ & $0 / 2$ & * \\
\hline Myrcia tomentosa & $0 / 3$ & $0 / 2$ & $0 / 1$ & * & * \\
\hline Plenckia populnea & $1 / 3$ & $0 / 3$ & $0 / 4$ & $0 / 4$ & $0 / 2$ \\
\hline Symplocos rhamnifolia & $1 / 4$ & $1 / 3$ & $0 / 2$ & $0 / 1$ & $*$ \\
\hline Espécies não-preferenciais & 1 a 2 & 3 a 5 & 6 a 10 & 11 a 20 & $>20$ \\
\hline Byrsonima verbascifolia & $10 / 4$ & $9 / 4$ & * & $*$ & * \\
\hline Kielmeyera coriacea & $10 / 5$ & $8 / 4$ & * & $*$ & $*$ \\
\hline Qualea grandiflora & $7 / 3$ & $6 / 3$ & $*$ & * & $*$ \\
\hline Stryphnodendron adstringens & $8 / 3$ & $8 / 3$ & $*$ & $*$ & $*$ \\
\hline Schefflera macrocarpa & $8 / 5$ & $6 / 5$ & $*$ & $*$ & * \\
\hline
\end{tabular}

em altitude ou classes de solos (Felfili \& Silva Júnior 1993; Felfili et al. 2001, 2004 e 2007). A ocorrência exclusiva ou diferencial no cerrado I na EEJBB com valores elevados de $\mathrm{D}$ e $\mathrm{AB}$ sugere maior habilidade competitiva em áreas no interflúvio. Estas devem ser, portanto, testadas em projetos de recuperação de áreas degradadas, em interflúvio, e em ampla faixa de variação de altitude e classes de solos cerrado sentido restrito no Brasil Central.

D. miscolobium, M. ferruginata, $M$. pohliana, $O$. hexasperma e $P$. rotundifolia apresentaram as maiores $\mathrm{D}$ e $\mathrm{AB}$ em
Latossolos na Chapada Pratinha. No cerrado I D. miscolobium, $M$. ferruginata e $O$. hexasperma apresentaram as maiores $\mathrm{D}$ e $\mathrm{AB}$ entre todas as 18 áreas comparadas. Este grupo de espécies foi, então, considerado indicador da condição de Latossolo em Interflúvio com potencial para projetos de recuperação de áreas degradadas.

Ouratea hexasperma com 290 ind.ha $^{-1}$ e $1,561 \mathrm{~m}^{2} \cdot$ ha $^{-1}$ no cerrado I, apresentou também D e AB elevados na FAL, IBGE e PNB em Latossolos e altitudes maiores que $1000 \mathrm{~m}$. As menores D e AB ocorreram em Latossolos 
Tabela 3 - Densidade (ind.ha-1) para espécies preferenciais aos cerrados sentido restrito de interflúvio (I) e vale (V) na Estação Ecológica do Jardim Botânico de Brasília (EEJBB) e em 18 áreas no Brasil Central. (PNB- Parque Nacional de Brasília, AE- Estação Ecológica de Águas Emendadas, BM- Parque Burle Marx, FAL- Fazenda Água Limpa, IBGE- Reserva Ecológica do IBGE, APA-APA do Paranóa- UnB, PRParacatu, PT-Patrocínio, SI- Silvânia, AP- Alto Paraíso, VP- Vila Propício, PNCV- Parque Nacional Chapada dos Veadeiros, SM- Serra da Mesa, SN- Serra Negra, RP- Formosa do Rio Preto, CO- Correntina, SD- São Desidério, PNSV- Parque Nacional Grande Sertão Veredas).

Table 3 - Density (ind.ha ${ }^{-1}$ ) of the preferential species from the cerrado sensu strictu of the interfluve (I) and the valley (V), at the Ecological Station of the Botanical Garden of Brasília (EEJBB) and 18 distinct areas at Central Brasil.(PNB- Parque Nacional de Brasília, AE- Estação Ecológica de Águas Emendadas, BMParque Burle Marx, FAL- Fazenda Água Limpa, IBGE- Reserva Ecológica do IBGE, APA-APA do Paranóa- UnB, PR-Paracatu, PT-Patrocínio, SI- Silvânia, AP- Alto Paraíso, VP- Vila Propício, PNCV- Parque Nacional Chapada dos Veadeiros, SM- Serra da Mesa, SN- Serra Negra, RP- Formosa do Rio Preto, CO- Correntina, SDSão Desidério, PNSV- Parque Nacional Grande Sertão Veredas).

\begin{tabular}{|c|c|c|c|c|c|c|c|c|c|c|c|c|c|c|c|c|c|c|c|c|}
\hline \multicolumn{3}{|l|}{ Espécies } & \multicolumn{6}{|c|}{$\begin{array}{l}\text { Chapada Pratinha } \\
\text { DF }\end{array}$} & \multicolumn{2}{|c|}{ MG } & \multicolumn{6}{|c|}{ Chapada dos Veadeiros } & \multicolumn{4}{|c|}{$\begin{array}{c}\text { Chapada São Francisco } \\
\text { BA/MG }\end{array}$} \\
\hline Preferenciais - Iinterflúvio & I & $\mathbf{V}$ & PNB & $\mathbf{A E}$ & $\mathbf{B M}$ & FAL & IBGE & APA & PR & PT & SI & $\mathbf{A P}$ & VP & PNCV & SM & $\mathbf{S N}$ & $\mathbf{R P}$ & $\mathrm{CO}$ & SD & PNSV \\
\hline Byrsonima coccolobifolia & 27 & 1 & 19 & 31 & 4 & 3,7 & 6 & 45 & 1 & 20 & 13 & 3 & 10,9 & 28,2 & 12,9 & 11,3 & 25 & 7 & 18 & 25 \\
\hline Caryocar brasiliense & 24 & - & 48 & 39 & 37 & 43,7 & 68 & 22 & 12 & 12 & 40 & - & 12,7 & 1,8 & 3,6 & 13,3 & - & - & - & 49 \\
\hline Dalbergia miscolobium & 79 & 10 & 16 & 4 & 11 & 24,7 & 46 & 37 & - & 64 & 3 & - & - & - & 0,7 & - & 6 & - & 7 & - \\
\hline Erythroxylum suberosum & 53 & 5 & 21 & 44 & 5 & 18,42 & 20 & 18 & 15 & 81 & 10 & 1 & 15,4 & 8,2 & 22,9 & 39,3 & 12 & 1 & 2 & 5 \\
\hline Miconia ferruginata & 57 & 1 & 2 & 3 & 1 & 7,9 & 40 & - & - & - & - & - & - & 23,4 & - & - & - & - & - & 4 \\
\hline Miconia pohliana & 31 & - & 2 & 7 & 1 & 62,6 & 2 & 8 & - & - & 1 & - & - & - & - & - & - & - & - & - \\
\hline Ouratea hexasperma & 290 & 13 & 117 & 66 & 69 & 145,8 & 156 & 63 & 2 & 5 & 24 & 16 & 15,4 & 14,6 & 24,3 & 28 & 4 & 22 & 26 & 14 \\
\hline Piptocarpha rotundifolia & 72 & - & 17 & 22 & 29 & 13,4 & 8 & 31 & 118 & 16 & 6 & - & 23,6 & - & - & 16 & - & - & - & 2 \\
\hline Pouteria ramiflora & 32 & - & 28 & 63 & 11 & 20,5 & 6 & 21 & - & - & 18 & 12 & 14,5 & 30,9 & 9,3 & 7,3 & 39 & 55 & 33 & 29 \\
\hline Pterodon pubescens & 28 & - & 7 & 7 & - & 10 & 6 & - & - & - & - & - & 4,5 & 4,6 & - & 10,7 & 12 & 5 & 11 & 6 \\
\hline \multicolumn{21}{|l|}{ Preferenciais - Vale } \\
\hline Dimorphandra mollis & 8 & 20 & 7 & 30 & 27 & 3,7 & 8 & 12 & 14 & 1 & 14 & - & 15,4 & 1,8 & 10 & 4 & 1 & 7 & 5 & 1 \\
\hline Eremanthus glomerulatus & 3 & 18 & 2 & 18 & 15 & 124,7 & 176 & - & 2 & 1 & 10 & 7 & 0,9 & - & - & - & - & - & 2 & - \\
\hline Eriotheca pubescens & 3 & 71 & 30 & 3 & 8 & 11 & 10 & 21 & 4 & - & 7 & - & - & 4,6 & - & - & - & - & - & 2 \\
\hline Guapira noxia & 12 & 41 & 15 & 15 & 6 & 20,0 & 98 & 1 & 1 & - & 3 & 7 & 4,5 & 6,4 & 5 & 0,7 & - & - & - & - \\
\hline Myrcia tomentosa & - & 9 & - & - & - & - & - & - & - & - & - & - & - & - & - & - & - & - & - & - \\
\hline Plenckia populnea & 1 & 17 & - & 5 & 2 & 1,6 & 2 & 40 & - & 9 & 11 & - & 0,9 & 0,9 & - & - & - & 5 & 4 & 1 \\
\hline Symplocos rhamnifolia & 3 & 26 & 1 & - & 9 & 5,3 & 28 & 2 & - & 2 & - & 1 & - & - & 0,7 & - & - & - & - & - \\
\hline \multicolumn{21}{|l|}{ Não-Preferenciais } \\
\hline Byrsonima verbascifolia & 63 & 12 & 23 & 37 & 2 & 8,4 & 4 & 6 & 7 & 18 & 12 & 28 & 14,5 & 13,4 & 17,1 & 16,7 & - & 5 & - & 11 \\
\hline Kielmeyera coriacea & 27 & 36 & 16 & 97 & 5 & 28,4 & 12 & 59 & 1 & 33 & 181 & 26 & 62,7 & - & 17,1 & 1 & 3 & 22 & 15 & 66 \\
\hline Qualea grandiflora & 32 & 7 & 56 & 34 & 6 & 50,5 & 58 & 12 & 19 & 104 & 192 & 14 & 52,7 & 5,5 & 36,4 & 81,3 & 5 & 16 & 30 & 38 \\
\hline Schefflera macrocarpa & 32 & 28 & 6 & 25 & 10 & 41,6 & 152 & 11 & 1 & 3 & 18 & 2 & 2,7 & 4,6 & 2,1 & - & - & - & - & - \\
\hline Stryphnodendron adstringens & 30 & 15 & 18 & 16 & 18 & 38,4 & 16 & 98 & 1 & 7 & 11 & - & 5,4 & 3,6 & 0,7 & - & - & 2 & - & - \\
\hline
\end{tabular}


Tabela 4-Área basal $\left(\mathrm{m}^{2} \cdot \mathrm{ha}^{-1}\right)$ para espécies preferenciais aos cerrados sentido restrito de interflúvio (I) e vale (V), na Estação Ecológica do Jardim Botânico de Brasília-DF e em 18 áreas no Brasil Central. (PNB- Parque Nacional de Brasília, AE- Estação Ecológica de Águas Emendadas, BMParque Burle Marx, FAL- Fazenda Água Limpa, IBGE- Reserva Ecológica do IBGE, APA-APA do Paranóa- UnB, PR-Paracatu, PT-Patrocínio, SI- Silvânia, AP- Alto Paraíso, VP- Vila Propício, PNCVParque Nacional Chapada dos Veadeiros, SM- Serra da Mesa, SN- Serra Negra, RP- Formosa do Rio Preto, CO- Correntina, SD- São Desidério, PNSV- Parque Nacional Grande Sertão Veredas).

Table 4-Basal area $\left(\mathrm{m}^{2} \cdot \mathrm{ha}^{-1}\right)$ of the preferential species from the cerrado sensu strictu in the restricted sense of the interfluve (I) and the valley (V), at the Ecological Station of the Botanical Garden of Brasília-DF and 18 distinct areas at Central Brasil. (PNB- Parque Nacional de Brasília, AE- Estação Ecológica de Águas Emendadas, BM- Parque Burle Marx, FAL- Fazenda Água Limpa, IBGE- Reserva Ecológica do IBGE, APA-APA do ParanóaUnB, PR-Paracatu, PT-Patrocínio, SI- Silvânia, AP- Alto Paraíso, VP- Vila Propício, PNCV- Parque Nacional Chapada dos Veadeiros, SM- Serra da Mesa, SN- Serra Negra, RP- Formosa do Rio Preto, CO- Correntina, SDSão Desidério, PNSV- Parque Nacional Grande Sertão Veredas).

\begin{tabular}{|c|c|c|c|c|c|c|c|c|c|c|c|}
\hline \multirow{3}{*}{$\begin{array}{l}\text { Espécies } \\
\text { Preferenciais - Interflúvio }\end{array}$} & \multicolumn{11}{|c|}{ Chapada Pratinha } \\
\hline & \multicolumn{8}{|c|}{ DF } & \multicolumn{2}{|c|}{ MG } & \multirow{2}{*}{$\begin{array}{l}\text { GO } \\
\text { SI }\end{array}$} \\
\hline & I & $\mathbf{V}$ & PNB & $\mathbf{A E}$ & BM & FAU & Miv & APA & PR & 11 & \\
\hline Byrsonima coccolobifolia & 0,079 & 0,002 & 0,258 & 0,155 & 0,020 & 0,010 & & 0,422 & 0,004 & 0,061 & 0,050 \\
\hline Caryocarbrasiliense & 0,263 & - & 0,607 & 0,695 & 0,760 & 0,564 & 0,740 & 0,867 & 0,151 & 0,144 & 0,413 \\
\hline miscolobium & 0,495 & 0,047 & 0,476 & 0,107 & 0,030 & 0,365 & 0,440 & 0,322 & - & 0,234 & 0,093 \\
\hline Erythroxylum suberosum & 0,146 & 0,017 & 0,798 & 0,1329 & 90,020 & 0,051 & 0,050 & 0,069 & 0,069 & 0,230 & 0,035 \\
\hline Miconia ferruginata & & 0,020 & & 0,053 & & & & - & - & - & - \\
\hline apohliana & 0,252 & - & 0,016 & 0,030 & 0,010 & 0,398 & 0,010 & 0,148 & 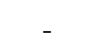 & - & 0,009 \\
\hline a hexasperma & 1,561 & 0,059 & 0,571 & 0,369 & 0,450 & 0,715 & & 0,390 & 0,013 & 0,019 & 0,160 \\
\hline Pipto & 0,314 & - & 0,083 & 0,125 & 0,020 & 0,044 & & 0,194 & 0,666 & 0,064 & 0,035 \\
\hline D & 372 & - & 0,195 & 0,486 & 0,130 & 0,232 & 0 & 0,331 & - & - & 0,244 \\
\hline Pterodon pubes & 5 & - & 0,036 & 0,215 & - & 0,099 & & - & - & - & - \\
\hline Droforemciais & & & & & & & & & & & \\
\hline & & 1 & 0,085 & 30,000 & $0 \quad 0,180$ & 3 & 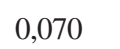 & 0,008 & 0,095 & 0,007 & 0,072 \\
\hline Ere & & & 005 & 18,000 & 00,060 & & & - & 0,006 & 0,002 & 0,033 \\
\hline 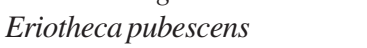 & 8 & 0,538 & 0,173 & 0,013 & 0,050 & 0,084 & 0 & 0,369 & 0,500 & - & 0,050 \\
\hline & 093 & 0,202 & 0,102 & 0,107 & 0,120 & 0,090 & 0,690 & - & 0,004 & - & 0,023 \\
\hline tosa & - & 0,033 & - & - & - & - & - & - & - & - & - \\
\hline &, 006 & 0,071 & & 0,020 & 0,010 & & & (2) & - & & 0,091 \\
\hline Symplocos rhamnifolia & 0,012 & 0,235 & 0,002 & - & 0,090 & 0,046 & 0,240 & - & - & 0,008 & - \\
\hline & & & & & & & & & & & \\
\hline folia & 1 & 054 & 0,119 & 0,130 & 0,030 & 0,044 & 0,0 & - & 0,018 & 0,081 & 0,047 \\
\hline & 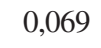 & & 0,054 & 0,418 & & & & 0,295 & & & 1,057 \\
\hline & 1 & 0,111 & 0,754 & 0,371 & 0,140 & 0, & 0 & 0,119 & 0,270 & 0,7 & 2,452 \\
\hline & & & 0,108 & 0,133 & 0,060 & & & - & 0,011 & 0,0 & 0,139 \\
\hline$n s$ & & 0,107 & 0,123 & 0, & 0,140 & & 090 & 1,222 & 0,004 & 0,060 & 0,063 \\
\hline & & Cha & G & ) & & & & BA & $\mathbf{I}$ & 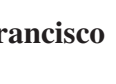 & \\
\hline ivio & & VI & PNC & & $\mathbf{S M}$ & & & $\mathrm{CO}$ & & & PNSV \\
\hline Byrs & 0,013 & 0,083 & 0,23 & & 0,148 & 0 & 0,132 & 0,041 & &, 108 & 0,147 \\
\hline brasiliense & - & 0,152 & 0,03 & & 0,080 & 0,188 & - & - & & - & 1,339 \\
\hline olobium & - & - & - & & 0,016 & - & 0,088 & - & & & - \\
\hline Erythrox & 0,00 & 0,08 & 0,02 & & 0,104 & 0,11 & 0,079 & 0,003 & &, 006 & 0,017 \\
\hline Miconia ferruginata & - & - & 0,22 & & - & - & - & - & & - & 0,081 \\
\hline Miconia pohliana & - & - & - & & - & - & - & - & & - & - \\
\hline Ouratea hexasperma & 0,05 & 0,088 & 0,05 & & 0,197 & 0,088 & 0,036 & 0,179 & &, 149 & 0,103 \\
\hline Piptocarphar & - & 0,156 & - & & - & 0,018 & - & - & & - & 0,023 \\
\hline Pouteria ramiflora & 0,10 & 0,142 & 0,36 & & 0,100 & 0,036 & 0,441 & 0,515 & &, 236 & 0,250 \\
\hline Pterodon pubescens & - & 0,020 & 0,02 & & - & 0,291 & 0,437 & 0,123 & &, 116 & 0,367 \\
\hline
\end{tabular}




\begin{tabular}{|c|c|c|c|c|c|c|c|c|c|}
\hline \multicolumn{10}{|l|}{ Preferenciais - Vale } \\
\hline Dimorphandra mollis & - & 0,082 & 0,023 & 0,108 & 0,017 & 0,020 & 0,067 & 0,030 & 0,016 \\
\hline Eremanthus glomerulatus & 0,024 & 0,002 & - & - & - & - & - & 0,006 & - \\
\hline Eriotheca pubescens & - & - & 0,020 & - & - & - & - & - & 0,020 \\
\hline Guapira noxia & 0,058 & 0,070 & 0,078 & 0,031 & 0,002 & - & - & - & - \\
\hline Myrcia tomentosa & - & - & - & - & - & - & - & - & - \\
\hline Plenckia populnea & - & 0,024 & 0,003 & - & - & - & 0,052 & 0,029 & 0,009 \\
\hline Symplocos rhamnifolia & 0,008 & - & - & 0,019 & - & - & - & - & - \\
\hline \multicolumn{10}{|l|}{ Não-Preferenciais } \\
\hline Byrsonima verbascifolia & 0,170 & 0,083 & 0,075 & 0,113 & 0,115 & - & 0,030 & - & 0,657 \\
\hline Kielmeyera coriacea & 0,152 & 0,395 & - & 0,178 & 0,002 & 0,023 & 0,178 & 0,124 & 0,406 \\
\hline Qualea grandiflora & 0,208 & 0,523 & 0,041 & 0,287 & 0,683 & 0,106 & 0,184 & 0,266 & 0,450 \\
\hline Schefflera macrocarpa & 0,007 & 0,008 & 0,021 & 0,001 & - & - & - & - & - \\
\hline Stryphnodendron adstringens & $s \quad-$ & 0,031 & 0,044 & 0,012 & - & - & 0,007 & - & - \\
\hline
\end{tabular}

e altitudes menores que $1.000 \mathrm{~m}$, em Paracatu (MG) e Patrocínio (MG) com 2 e 5 ind.ha ${ }^{-1}$ respectivamente (Felfili \& Silva Júnior 1993; Felfili et al. 2004). Moreira (1992) indicou sua maior importância (IVI) em áreas frequentemente queimadas, como é o caso na EEJBB, FAL, IBGE e PNB no DF. A frequência de incêndios e a altitude devem ser variáveis consideradas em experimentos com esta espécie.

No Jardim Botânico de Brasília, Miconia ferruginata, M. pohliana, tal qual $O$. hexasperma, foram amostradas com densidades elevadas na Estação Ecológica (EEJBB) que tem sofrido queimadas em intervalos de cerca de 5 anos. Por outro lado, na área de visitação, totalmente acerada e com baixa ocorrência de incêndios, Miconia burchelli ocorre com populações maiores (Silva Júnior et al., dados não publicados). Experimentação com Miconia spp. em cerrado sentido restrito pode fornecer dados importantes do manejo para a conservação do cerrado.

Pouteria ramiflora, exclusiva no cerrado I com 32 ind.ha ${ }^{-1}$, ocorreu em 15 áreas, com destaque nas quatro áreas associadas a Neossolos Quartzarênicos na CS com 29 a 55 ind.ha ${ }^{-1}$. No DF, ocorreu com 19,9 \pm 6 ind.ha ${ }^{-1}$ em 10 áreas de cerrado sentido restrito preservadas (Nunes et al. 2002). Destaca-se seu potencial para recuperação de áreas degradadas em Latossolo, no interflúvio, e em Neossolos Quatzarênicos.

$P$. pubescens apresentou os valores mais altos de D no cerrado I na EEJBB (28 ind.ha $\left.{ }^{-1}\right)$ e as mais altas AB nas áreas de Serra NegraGO $\left(0,291 \mathrm{~cm}^{2} \cdot \mathrm{ha}^{-1}\right)$, em solos Litólico, e em Formosa do Rio Preto-BA $\left(0,437 \mathrm{~cm}^{2} . \mathrm{ha}^{-1}\right)$, em solo arenoso. No DF, ocorreu com 10,7 \pm 3 ind.hat e 0,1695 $\pm 0,0547 \mathrm{~cm}^{2} \cdot \mathrm{ha}^{-1}$ em 10 localidades associadas a Latossolos. Seu destaque em áreas sobre latossolos, solos litólicos e arenosos em ampla distribuição geográfica, no indicou seu caráter generalista no Brasil Central.

\section{Espécies preferenciais ao vale $(\mathrm{V})$}

As espécies preferenciais ao vale (Tab. 2) incluíram Dimorphandra mollis $\left(9^{\mathrm{a}} \times 29^{\mathrm{a}}\right.$ IVI em V $\times$ I), Eremanthus glomerulatus $\left(12^{\mathrm{a}}\right.$ $\left.\times 38^{\mathrm{a}}\right)$, Eriotheca pubescens $\left(1^{\mathrm{a}} \times 43^{\mathrm{a}}\right)$, Guapira noxia $\left(3^{\mathrm{a}} \times 26^{\mathrm{a}}\right)$, Myrcia tomentosa $\left(19^{\mathrm{a}}\right)$, Plenckia populnea $\left(13^{\mathrm{a}} \times 50^{\mathrm{a}}\right)$ e Symplocos rahmnifolia $\left(5^{\mathrm{a}} \times 47^{\mathrm{a}}\right)$. Apenas $M$. tomentosa foi exclusiva na área. Entre as 18 áreas comparadas, E. pubescens apresentou os maiores valores de D e AB, enquanto E. glomerulatus, G. noxia, P. populnea e S. rahmnifolia apresentaram os segundos e $D$. mollis os terceiros maiores valores de $\mathrm{D}$ e $\mathrm{AB}$ no cerrado $\mathrm{V}$.

M. tomentosa é espécie típica de bordas de matas de galeria no Brasil Central e não foi amostrada em qualquer das outras áreas comparadas. Ocorreu, entretanto, em três das cinco parcelas no cerrado $\mathrm{V}$, dada a proximidade da área com a borda da mata de galeria do córrego Cabeça-de-Veado na EEJBB.

D. mollis, E. glomerulatus, E. pubescens, $G$. noxia e $P$. populnea ocorreram em pelo 
menos oito das nove áreas comparadas em Latossolos na Chapada Pratinha, na maioria das vezes melhor representadas em áreas no DF em altitudes maiores que $1.000 \mathrm{~m}$ (Felfili \& Silva Júnior 1993). No DF, D. mollis, E. glomerulatus, E. pubescens, G. noxia apresentaram D e AB maiores ou na Estação Ecológica de Águas Emendadas (AE) ou no Parque Nacional de Brasília (PNB) ou no Parque Burle Marx (BM), três áreas associadas a Latossolos e avaliadas sob a influência de lençol freático mais superficial (Nunes 2001), fato que corrobora a associação destas espécies com o cerrado de Vale na EEJBB. Na Chapada dos Veadeiros, em solos Litólicos e Cambissolos e na Chapada São Francisco em Neossolos Quartzarênicos apresentaram populações menores.

E.pubescens é espécie frequentemente amostrada em bordas de matas de galeria no Brasil Central. Na Reserva Ecológica do IBGE, vizinha da EEJBB, nas matas do Pitoco e Taquara, foi amostrada com 75,1 e 28,1 ind.ha ${ }^{-1}$, respectivamente (Silva Júnior 2004, 2005).

P. populnea, com 17 ind.ha ${ }^{-1}$ no cerrado $\mathrm{V}$, ocorreu com 40 ind.ha ${ }^{-1}$ na APA do Paranoá (Assunção \& Felfili 2004), área amostrada na vizinhança do Lago Paranoá em Brasília, provavelmente sob a influência de maior disponibilidade de água. Esta espécie frequentemente coloniza as bordas de matas de galeria no Brasil Central.

As comparações com as 18 áreas associadas à distribuição diferencial nos cerrados V e I credenciam Dimorphandra mollis, Eremanthus glomerulatus, Eriotheca pubescens, Guapira noxia, Plenckia populnea e Symplocos rahmnifolia, indicadoras da condição de vale associadas à Cambissolos.

\section{Espécies não-preferenciais}

B. verbascifolia ocorreu em nas 10 parcelas I e em quatro parcelas V. Foi espécie de ampla distribuição e indicada como indiferente em 11 áreas associadas à Latossolos na CP e Cambissolos e solos Litólicos na CV (Haridasan 2007; Felfili et al.
2007). Consta da listas de espécies de ampla distribuição no cerrado por ocorrer em 50\% das 376 localidades estudadas no Cerrado (Ribeiro et al. 2005). Ocorreu em 12 das 18 áreas comparadas com mais de 10 ind.ha $^{-1} \mathrm{e}$ nos cerrado I e V com populações de 63 e 12 ind.ha ${ }^{-1}$, respectivamente. Resultados que lhe conferem caráter generalista, embora, com a habilidade de estabelecer 5,25 vezes mais indivíduos no cerrado I na EEJBB.

$K$. coriacea foi amostrada nas 15 parcelas I e V com 1 a 2 indivíduos e em 12 destas com até 5 indivíduos, comportamento claramente não-preferencial quanto à topografia ou classe de solos na EEJBB. As densidades de 27 e 36 ind.ha $^{-1}$ encontradas nas áreas I e V, respectivamente, estão dentro do IC de 38,6 $\pm 11,1$ ind.ha ${ }^{-1}$ calculado para o DF onde foi amostrada em 69 de 100 parcelas (Nunes et al. 2002). Na Chapada Pratinha (DF, GO e MG) foi indiferente em 6 localidades associadas a Latossolos (Felfili \& Silva Júnior 1993). Apresentou D maiores que 60 ind.ha $^{-1}$ em pelo menos uma das áreas nas Chapadas dos Veadeiros e São Francisco (Felfili et al. 2004, 2007). Assim, sua ampla distribuição geográfica e capacidade de recrutar indivíduos em diferentes classes de solos e altitudes no Brasil Central a caracterizam com espécie generalista, indiferente a variações topográficas e de classes de solos na EEJBB. $K$. coriacea ocupa a $8^{\mathrm{a}}$ posição na lista das espécies mais amplamente distribuídas no cerrado sentido restrito por ter ocorrido em $70 \%$ das 376 localidades estudadas (Ribeiro et al. 2005).

Qualea grandiflora foi amostrada em 6 parcelas I e em 3 parcelas V com até cinco indivíduos e ocorreu em todas as 18 áreas comparadas (Felfili et al. 2004, 2007), em 10 das quais com populações maiores que 32 ind.ha ${ }^{-1}$, densidade anotada para o cerrado I. Seu comportamento é claramente nãopreferencial no Brasil Central. Q. grandiflora é a espécie mais amplamente distribuída no cerrado brasileiro onde ocorreu em $85 \%$ de 376 localidades estudadas (Ribeiro et al. 2005). 
Stryphnodendron adstringens foi amostrado em 11 parcelas, 8 na comunidade I e 3 na V, com até 5 indivíduos, o que lhe conferiu 30 e 15 ind.ha $^{-1}$ na comparação I x V. Ocorreu também em 12 de 18 áreas comparadas no Brasil Central com populações menores nos solos Litólicos e Cambissolos na Chapada dos Veadeiros e muito pouco representada nos Neossolos Quatzarênicos na Chapada São Francisco (Felfili \& Silva Júnior 1993; Felfili et al. 2001, 2004, 2007). Seu caráter generalista afirmado principalmente para áreas associadas aos Latossolos.

Schefflera macrocarpa ocorreu em $8 \times$ 5 parcelas com 1 a 2 indivíduos e em 6 x 5 parcelas com até 5 indivíduos na relação I $\mathrm{x}$ V. Ocorreu em 13 das 18 áreas comparadas no Brasil Central, com exceção dos solos arenosos na CS (Felfili \& Silva Júnior 1993; Felfili et al. 2001, 2004, 2007). Suas populações nas áreas I e V foram maiores que aquelas anotadas em 11 das 18 áreas comparadas. Apresenta-se aqui seu caráter indiferente a situações topográficas e solos (Latossolos ou Litólicos), com ausência de representação em solos arenosos, porém com o dobro da representação, 30 ind.ha $^{-1}$, no interflúvio, em relação aos 15 ind.ha $^{-1}$ amostrados em Cambissolos de Vale na EEJBB.

Resultados semelhantes foram encontrados por Henriques (2004) que estudou o cerrado sentido restrito na Reserva Ecológica do IBGE, 50, 250 e $300 \mathrm{~m}$ distantes da borda da mata de galeria do Taquara. Eriotheca pubescens apresentou densidade acentuadamente maior na borda da mata, tal qual no cerrado de vale na EEJBB. O autor comentou que o lençol freático deve ser mais superficial na área de vale. Situação contrária foi observada para Ouratea hexasperma com maiores densidades a 250 e $300 \mathrm{~m}$ da borda da mata, provavelmente devido sua intolerância a maior umidade no solo.

$\mathrm{Na}$ EEJBB a proximidade entre as áreas I e V (Fig. 2) não sugere a impossibilidade de acesso de sementes por qualquer estratégia de dispersão. A variação topográfica, suas consequências no regime hídrico e nas propriedades químicas e físicas dos solos devem responder por grande parte das variações detectadas.

\section{Conclusões}

Aceita-se a hipótese de que o efeito da topografia sobre outros fatores ambientais contribuiu para diferenças florísticas e estruturais ao nível de espécies e de comunidades do componente lenhoso do cerrado sentido restrito em duas posições topográficas, interflúvio (I) e vale (V), na Estação Ecológica do Jardim Botânico de Brasília (EEJBB).

A estratégia de avaliar a fitossociologia nas duas áreas, a distribuição espacial das populações pelo TWINSPAN e de comparar a densidade e área basal das espécies com distribuição preferencial em 18 áreas no Brasil Central validou as diferenças encontradas nos cerrado I e V na EEJBB.

As seguintes espécies foram consideradas indicadoras potenciais de diferentes classes de solos, ou diferentes altitudes, ou posições topográficas no cerrado sentido restrito no Brasil central:

- Latossolos em interflúvio, por serem exclusivas no cerrado I: Blepharocalyx salicifolius, Miconia pohliana, Piptocarpha rotundifolia, Pouteria ramiflora, Pterodon pubescens e Sclerolobium paniculatum;

- Latossolos em interflúvio, por sua importância fitossociológica no cerrado I: Ouratea hexasperma, Dalbergia miscolobium, Qualea parviflora e Miconia ferruginata e Piptocarpha rotundifolia;

- Latossolos, solos Litólicos, Cambissolos ou Neossolos Quatzarênicos, em interflúvio, por serem preferenciais ao cerrado I e por sua distribuição densidade e área basal em 18 áreas no Brasil Central: Byrsonima coccolobifolia, Caryocar brasiliense e Erythroxylum suberosum;

- Latossolos em interflúvio, por serem preferenciais ao cerrado I e por sua distribuição 
densidade e área basal em 18 áreas no Brasil Central: Dalbergia miscolobium, Miconia ferruginata, $M$. pohliana, Ouratea hexasperma, Piptocarpha rotundifolia;

- Latossolos e Neossolos Quatzarênicos, em interflúvio, por serem preferenciais ao cerrado I e por sua distribuição densidade e área basal em 18 áreas no Brasil Central: Pouteria ramiflora.

As seguintes espécies foram consideradas indicadoras potenciais de Cambissolos em área de Vale no Brasil central:

- por sua importância fitossociológica no cerrado V: Eriotheca pubescens, Guapira noxia, Qualea multiflora e Symplocos rhamnifolia;

- por serem preferenciais ao cerrado $\mathrm{V}$ na classificação pelo TWINSPAN: Dimorphandra mollis, Eremanthus glomerulatus, Eriotheca pubescens, Guapira noxia, Myrcia tomentosa, Plenckia populnea e Symplocos rhamnifolia;

As espécies não preferenciais, indiferentes à variação na topografia na EEJBB foram: Byrsonima verbascifolia, Kielmeyera coriacea, Qualea grandiflora, Stryphnodendron adstringens e Schefflera macrocarpa.

Entre essas as seguintes foram consideradas amplamente generalistas ou indicadores potenciais de diferentes classes de solos, ou diferentes altitudes, ou posições topográficas no cerrado sentido restrito no Brasil central:

- generalista com a habilidade de estabelecer mais indivíduos no interflúvio na EEJBB, Byrsonima verbascifolia;

- generalistas, indiferentes a variações topográficas na EEJBB e altitudes e classes de solos no Brasil central, Kielmeyera coriacea, Qualea grandiflora;

- generalista, principalmente associada aos Latossolos, Stryphnodendron. Adstringens;

- generalista, principalmente associada aos Latossolos ou solos Litólicos, Schefflera macrocarpa com a habilidade de estabelecer mais indivíduos no interflúvio na EEJBB.
A topografia e sua influência nos níveis do lençol freático, no regime de umidade e nos parâmetros químicos e físicos dos solos devem ser avaliados em estudos futuros para a melhor compreensão da heterogeneidade florística apresentada.

\section{REFERÊNCIAS BibLIOGRÁFICAS}

Adámoli, J.; Macedo, J.; Azevedo, L. G. \& Madeira Neto, J. 1985. Caracterização da região dos Cerrados. In: Goedert, W.J . (ed.). Solos dos cerrados. EMBRAPA, Brasília. Pp. 33-73.

Angiosperm Phylogeny Group II. 2003. An update of the angiosperm phylogeny group classication for the orders and families of flowering plants: APG II. Botanical Journal of the Linnean Society 141(4): 399-436.

Assunção, S. L. \& Felfili, J. M. 2004. Fitossociologia de um fragmento de cerrado (s.s) na APA do Paranoá, DF. Acta Botanica Brasilica 18(4): 903-909.

Azevedo, L. G.; Ribeiro, J. R.; Schiavini, I. \& Oliveira, P. E. A. M. 1990. Levantamento da vegetação do Jardim Botânico de Brasília-DF. Fundação Zoobotânica, Brasília, DF, 92p.

Eiten, G. 1972. The Cerrado vegetation of Brazil. Botanical Review 38(2): 201-341.

Eiten, G. 1994. Vegetação do cerrado. In: Pinto, M. N. (ed.). Cerrado: caracterização, ocupação e perspectivas. 2ed. UnB/ Sematec, Brasília. Pp. 9-65.

EMBRAPA. 1999. Sistema brasileiro de classificação de solos. EMBRAPA, Rio de Janeiro. 412 p.

Fechner, H. R. 2001. Sobrevivência de árvores no Cerrado (sensu stricto) após fogo, no Jardim Botânico de Brasília-DF. Monografia de Graduação. UnB, Brasília, 15p.

Felfili, J. M. 2000. Diversidade florística das áreas nucleares da Reserva da Biosfera do Cerrado-Fase I. In: Vegetação no Distrito Federal-tempo e espaço. UNESCO/Brasil. Pp. 29-74.

Felfili, J. M.; Silva Júnior, M. C. 1993. A comparative study of cerrado (sensu 
stricto) vegetation in Central Brazil. Journal of Tropical Ecology 9: 277-289.

Felfili J. M.; Silva Júnior. M. C.; Rezende, A. V.; Machado, J. M. B.; Walter, B. M. T.; Silva, P. E. N. \& Hay, J. D. 1993. Análise comparativa da florística e fitossociológia da vegetação arbórea do cerrado sensu stricto na Chapada Pratinha, DF-Brasil. Acta Botanica Brasilica 6(2): 27-46.

Felfili, J. M.; Filgueiras, T.S.; Haridasan, M.; Silva Júnior, M. C.; Mendonça, R. \& Rezende, A. V. 1994. Projeto biogeografia do bioma cerrado: vegetação e solos. Cadernos de Geociências do IBGE 12: 75-166.

Felfili, J. M.; Sevilha, A. C. \& Silva Júnior, M. C. 2001. Comparação entre as unidades de fisiográficas da Chapada Pratinha, Veadeiros e Espigão Mestre do São Francisco. In: Felfili, J. M. \& Silva Júnior M. C. (eds.). Biogeografia do bioma cerrado-Chapada do Espigão Mestre do São Francisco. Programa Nacional de Florestas, Brasília. Pp. 80-94.

Felfili, J. M.; Silva Júnior, M. C.; Sevilha, A. C; Fagg, C. W.; Walter, B. M. T.; Nogueira, P. E. \& Rezende, A. V. 2004. Diversity, floristic and structural patterns of cerrado vegetation in Central Brazil. Plant Ecology 175: 37-46.

Felfili, J. M.; Sevilha, A. C. \& Silva Júnior, M. C. 2007. Comparação entre as unidades fisiográficas: Chapada Pratinha e Chapada dos Veadeiros. In: Felfili, J. M.; Rezende, A. V. \& Silva Júnior, M. C. (eds.). Biogeografia do bioma cerrado-vegetação e solos da Chapada dos Veadeiros. Editora UnB. Brasília. Pp. 113-117.

Ferreira, J.; Bustamante, M.; Garcia-Montiel, D.; Caylor, K. \& Davidson, E. 2007. Spatial variation in vegetation structure coupled to plant available water determined by two-dimensional soil resistivity profiling in a Brazilian savanna. Oecologia 153 (2): 417-430.

Fonseca, M. S. \& Silva Júnior, M. C. 2004. Fitossociologia e similaridade florística entre trechos de cerrado sentido restrito em interflúvio e em vale no Jardim Botânico de Brasília-DF. Acta Botanica Brasilica 18(1): 19-29.

Franco, A. C. 2002. Ecophysiology of woody plants. In: Oliveira, P. S. \& Marquis, R. J. (org.). The cerrados of Brazil: ecology and natural history of a neotropical savanna. 1 ed. Columbia University Press, New York. Pp. 178-197.

Frost, P. G. H.; Medina, E.; Menault, J. C.; Solbrig, O.; Swift, M. \& Walker, B. 1986. Responses of savannas to stress and disturbances. Biology International (special issue) 10: 1-82.

Haridasan, M. 2007. Solos. In: Felfili, J. M.; Rezende, A. V. \& Silva Júnior, M. C. (ed.). Biogeografia do bioma cerradoChapada dos Veadeiros. Ed. UnB, Brasília. Pp. 27-43.

Henriques, R. P. B. 2004. Análise fitossociológica em vegetação de cerrado sensu stricto em um gradiente topográfico no Brasil Central. Boletim do Herbário Ezechias Paulo Heringer 13: 61-84.

Henriques, R. P. B. \& Hay, J. D. 2002. Patterns and dynamics of plant populations. In: Oliveira, P. S. \& Marquis, R. J. (eds.). The cerrados of Brazil. Ecology and natural history of a neotropical savanna. Columbia University Press, New York. Pp. 140-158.

Hill, M. O. 1979. TWINSPAN: a FORTRAN program for arranging multivariate data in an ordered two-way table by classification, and its application to a survey of native pinewoods in Scotland. Journal of Ecology 63: 597-613.

Jongman, R. H. G.; Ter Braak, C. J. F.; Van Tongeren, O. F. R. 1987. Data analysis in community and landscape ecology. Pudoc.Wageningen.

Ledru, M. P. 2002. Late quaternary history and evolution of the cerrados as revealed by palinological records. In: Oliveira, P. S. \& Marquis, R. J. (eds.). The cerrados of Brazil. Ecology and natural history of a neotropical savanna. Columbia University Press, New York. Pp. 33-50. 
Mendonça, R. C.; Felfili, J. M.; Walter, B. M. T.; Silva Júnior, M. C.; Rezende, A. V.; Filgueiras, T. S. \& Nogueira, P. E. 1998. Flora vascular do cerrado. In: Sano, S. \& Almeida, S. (eds.). Cerrado ambiente e flora. EMBRAPA, Planaltina. Pp 289-556.

Miranda, H. S.; Bustamante, M. M. C.\& Miranda, A. C. 2002. The fire factor. In: Oliveira, P. S. \& Marquis, R. J. (eds.). The cerrados of Brazil. Ecology and natural history of a neotropical savanna. Columbia University Press, New York. Pp. 51-68.

Mittermeier, R. A.; Gil, P. R.; Hoffmann, M.; Pilgrim, J.; Brooks, T.; Mittermeier, C. G.; Lamourex, J. \& Fonseca, G. A. G. 2005. Hotspots revisited. Earth's biologically richest and most endangered terrestrial ecorregions. CI, Washington . Pp. 15-96.

Moreira, A. G. 1992. Fire protection and vegetation dynamics in the brazilian cerrado. Ph.D. thesis. Harvard University, Cambridge, 235p.

Nunes, R. V. 2001. Padrões de distribuição geográfica de espécies lenhosas do cerrado (sentido restrito) no Distrito Federal. Dissertação de Mestrado. UnB, Brasília, 58p.

Nunes, R. V.; Silva Júnior, M. C.; Felfili, J. M. \& Walter, B. M. T. 2002. Intervalos de classe para a abundância, dominância e frequência do componente lenhoso do cerrado sentido restrito no Distrito Federal. Revista Árvore 26 (2): 173-182.

Oliveira-Filho, A. T. \& Ratter, J. A. 2002. Vegetation physiognomies and woody flora of the cerrado biome. In: Oliveira, P. S. \& Marquis, R. J. (eds.). The cerrados of Brazil. Ecology and natural history of a neotropical savanna. Columbia University Press, New York. Pp. 91-120.

Pereira, B. A. S. 2008. Fitogeografia e relação vegetação-ambiente em florestas estacionais deciduais sobre afloramentos calcários no Brasil Central e em zonas de transição com a caatinga e com a Amazônia. Tese de Doutorado. UnB, Brasília, 108p.
Ratter, J. A.; Bridgewater, S. \& Ribeiro, J.F. 2003. Analysis of the floristic composition of the brazilian Cerrado vegetation III: comparison of the woody vegetation of 376 areas. Edinburgh Journal of Botany 60(1): 57-109.

Ratter, J. A; Ribeiro, J. F. \& Bridgewater, S. 1997. The Brazilian cerrado vegetation and threats to its biodiversity. Annals of Botany 80: 223-230.

Ribeiro, J. F. \& Walter, B. M. T. 2008. As principais fitofisionomias do bioma cerrado. In: Sueli Matiko Sano; Semíramis Pedrosa de Almeida; José Felipe Ribeiro. (orgs.). Cerrado: ecologia e flora. 1 ed. v. 1. Embrapa Cerrados/Embrapa Informação Tecnológica, Brasília. Pp. 151-212.

Ribeiro, J. F.; Bridgewater, S.; Ratter, J. A. \& Sousa-Silva, J. C. 2005. Ocupação do bioma cerrado e conservação da sua diversidade vegetal. In: Scariot, A., SousaSilva, J. C. \& Felfili, J. M. (eds.). Cerrado: ecologia biodiversidade e conservação. MMA, Brasília. Pp. 385-399.

Rodriguez-Iturbe, I.; Porporato, A.; Laio, F. \& Ridolfi, F. 2001. Plants in water-controlled ecosystems: active role in hydrologic processes and response to water stress I. Scope and general outline. Adv. Water Res 24: 695-705.

Rossi, C. V.; Silva Júnior, M. C. \& Santos, C. E. N. 1998. Fitossociologia do estrato arbóreo do cerrado sensu stricto no Parque Ecológico Norte, Brasília-DF. Boletim do Herbário Ezechias Paulo Heringer 2: 49-56.

Sarmento, T. R. \& Silva Júnior, M. C. 2006. Composição florística e fitossociologia das comunidades lenhosas do cerrado sentido restrito em duas posições topográficas no Jardim Botânico de Brasília, DF. Boletim do Herbário Ezechias Paulo Heringer 16: $12-22$.

Sarmento, T. R. \& Silva Júnior, M.C. 2008. Classificação do cerrado sentido restrito de interflúvio e vale na Estação Ecológica do Jardim Botânico de Brasília, DF. $5^{\circ}$ 
Simpósio de Pós-graduação em Ciências Florestais. Vol. 1 em CD.

Silva Júnior, M. C. 2004. Fitossociologia e estrutura diamétrica da mata de galeria do Taquara, na Reserva Ecológica do IBGE, DF. Revista Árvore 28 (3): 419-428.

Silva Júnior, M. C. 2005. Fitossociologia e estrutura diamétrica na mata de galeria do córrego Pitoco, na Reserva Ecológica do IBGE, DF. Revista Cerne 11(2): 147-15.

Solbrig, O. T. 1996. The diversity of the savanna ecosystem. In: Solbrig O. T.; Medina E.;
Silva, J. F. (eds.). Biodiversity and savanna ecosystem processes - A global perspective. Ecological Studies, v.121. Springer, Berlin. Walter, B. M. T. 2006. Fitofisionomias do Bioma Cerrado: síntese terminológica e relações florísticas. Tese de Doutorado. UnB, Brasília, 373p.

Walter, H. 1986. Vegetação e zonas climáticas. EPU, SãoPaulo, 237p. 